\title{
"What if this is my chance to save my life?" The patient perspective on public solicitation of living kidney donors
}

\author{
Mathilde Pronk ${ }^{(1)}$, Dorthe Slaats ${ }^{(1)}$, Willij Zuidema ${ }^{(1)}$, Medard Hilhorst ${ }^{(2)}$, Frank Dor ${ }^{(1)(3)}$, Michiel Betjes(1), \\ Willem Weimar ${ }^{(1)}$,Jacqueline van de Wetering ${ }^{(1)}$, Emma K. Massey ${ }^{(1)}$
}

(1) Dept. of Internal Medicine, Erasmus MC, Rotterdam, The Netherlands; (2) Dept. of Medical Ethics and Philosophy, Erasmus MC, Rotterdam, The Netherlands; (3) Dept. of Renal and Transplant Services, Hammersmith hospital, London, UK

\section{Introduction}

An increasing number of patients use public solicitation (PS) to find a living kidney donor. This development has given rise to a debate about the ethical complexities of PS. This study aimed to give a much needed voice to patients in this discussion. We investigated why endstage renal disease (ESRD) patients decided to engage in PS and what they experienced during the process of PS.

\section{Methods}

- Dutch kidney patients who publicly solicited a living kidney donor between 2011 and 2015 were invited to participate in this study.

- Patients were identified by searching Google, Facebook and Twitter.

- Patients were eligible for the study if they were over 18 years of age, had sufficient command of the Dutch language to participate in the interview and if their contact details were publicly available.

- Semi-structured interviews were conducted with participants in their homes. Topics included decision-making, experiences finding a donor in social network, considerations prior to PS, experiences with PS and with potential donors.

- Interviews were analyzed for general themes using the constant comparison method, described in Grounded Theory.

\begin{tabular}{|l|l|}
\hline \multicolumn{2}{|l|}{ Table 1. Medical characteristics of participants ( $\mathrm{N}=20)$} \\
\hline \multicolumn{2}{|c|}{$\boldsymbol{n}$} \\
\hline Blood type & 12 \\
O & 5 \\
A & 3 \\
B & \\
\hline Type of RRT before PS & 15 \\
Dialysis/CAPD & 5 \\
\hline No RRT (yet) & $49.81(60.50)$ \\
\hline Mean months of dialysis before PS (SD) & \\
\hline Number of transplants before PS & 13 \\
0 & 3 \\
1 & 4 \\
\hline $2-4$ & \\
\hline Transplant status at time of interview & 11 \\
Not transplanted (yet) & 4 \\
Transplanted via PS & 1 \\
Transplanted via unspecified donor & 4 \\
Transplanted via deceased donor waitlist & \\
\hline
\end{tabular}

\section{Results}

- 20 ESRD patients participated (response rate $50 \%$ ).

- Average age was 46 (range 26 to 74). 12 were male, 13 had undergone further education. All were European. 7 had a below average income, 4 average and 7 above average.

- Participants had often used multiple methods in their public search for a living donor such as Facebook, Twitter, Newspapers, Personal website, Radio, TV, YouTube and bumper stickers.

- Participants medical characteristics are presented in Table 1.

- Themes are presented in Figure 1.

\begin{tabular}{|c|c|c|}
\hline $\begin{array}{l}\text { Barriers to finding a } \\
\text { donor }\end{array}$ & 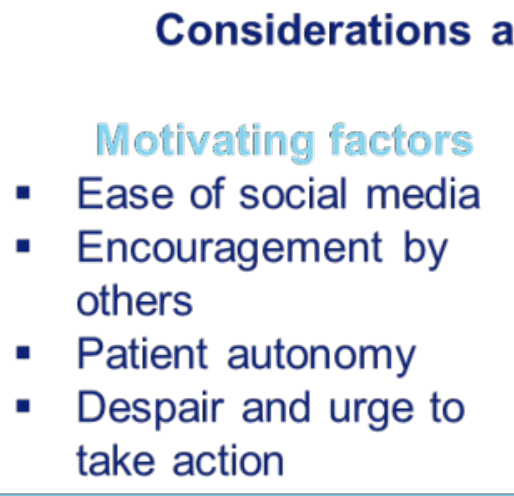 & $\begin{array}{l}\text { ut public solicitation } \\
\text { Inhibiting factors } \\
\text { - Public disclosure and } \\
\text { vulnerability } \\
\text { - Fear of being } \\
\text { (perceived to be) selfish }\end{array}$ \\
\hline & $\begin{array}{l}\text { Decision to engage in } \\
\text { public solicitation } \\
\text { - Emotional process }\end{array}$ & \\
\hline \multicolumn{3}{|c|}{ Experiences during public solicitation } \\
\hline $\begin{array}{l}\text { - Hope } \\
\text { - Support } \\
\text { - Positive donor candidate } \\
\text { - Helpful skills and persona } \\
\text { - Varying donors motives }\end{array}$ & 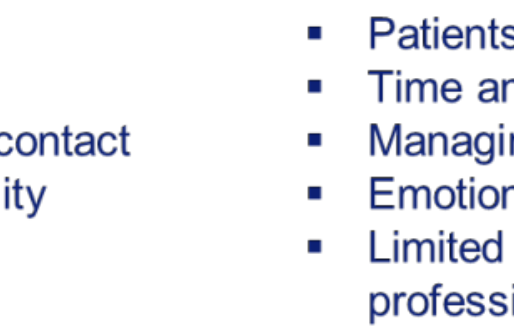 & $\begin{array}{l}\text { s health professionals } \\
\text { energy consuming } \\
\text { unequal relationships } \\
\text { y taxing process } \\
\text { operation from health } \\
\text { als }\end{array}$ \\
\hline
\end{tabular}

Figure 1. Factors influencing the decision of ESRD-patients to engage in public solicitation and their experiences with public solicitation.

Illustrative quotes

Despair and urge to take action "The necessity became more and more clear to me. I grew up with three dialysis buddies. They all died within a year. They were my peers. (...) And that contributed to me being more open about it. To me starting searching for a donor again. Using controversial methods to find my match."

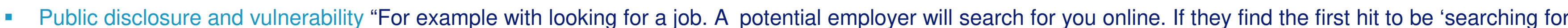
a kidney', that's not really promising."

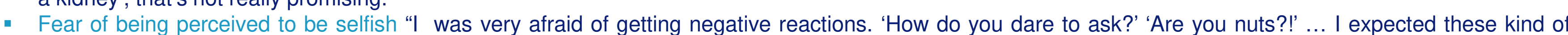
reactions."

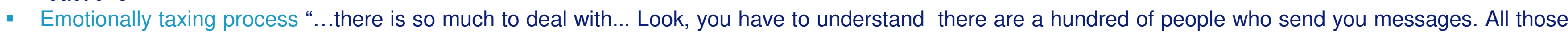
hundreds of people you have to keep responding to, because otherwise it just dies a death."

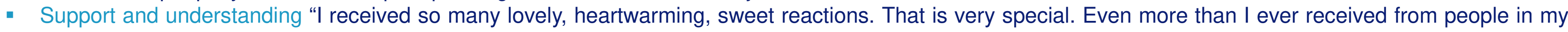
own environment. You know. That's really great."

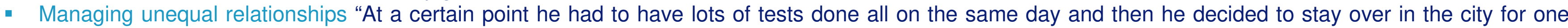
night so he could undergo the tests the next day. So then we said: should we pay for that or what?"

\section{Discussion}

These results call for improved communication about the new Dutch policy on PS with patients who are considering engaging in PS, and the development of better support systems to relieve patients of their screening and educating role during the PS process. Greater openness by professionals about this topic may encourage patients to discuss their donor search prior to undertaking PS and create an opportunity for education and counseling during the process. These results can inform and complement (existing) policies on PS and provide suggested content for education of patients who are considering engaging in PS. 